\title{
USO DE POLÍMEROS HIDRORETENTORES NA PRODUÇÃO DE PALMA FORRAGEIRA
}

\section{USE OF HIDRORETENTORES POLYMERS IN FORAGE PALM \\ PRODUCTION}

Apresentação: Pôster

\author{
Pablo Ramon da Costa ${ }^{1}$; Sueni Medeiros do Nascimento ${ }^{2}$; Brena Karisia Campos de \\ Melo $^{3}$; Alysson Lincoln da Silva Júnior ${ }^{4}$; Emerson Moreira de Aguiar ${ }^{5}$
}

\section{DOI: $\underline{\text { https://doi.org/10.31692/2526-7701.IIICOINTERPDVAGRO.2018.00688 }}$}

\section{Introdução}

Os sistemas produtivos agrícolas e agropecuários são baseados na forma de exploração e na disponibilidade de água sendo a mesma, um fator determinante para a produção dentro destes sistemas, pois há um elo entre a relação solo-água-planta que reflete na produção da cultura (TAIZ e ZEIGER, 2009), sendo assim buscam-se formas de reduzir possíveis efeitos negativos do déficit hídrico sob as culturas.

A pecuária em regiões áridas e semiáridas figura como um importante contribuinte para fomentação de renda aos produtores. Considerando que as cactáceas forrageiras são facilmente adaptadas ao semiárido brasileiro e a palma é uma das principais culturas xerófilas a nível mundial, o cultivo e uso destas cactáceas viabilizou os sistemas pecuários no semiárido. O tipo de metabolismo da palma lhe confere características que permitem maior eficiência na utilização do recurso hídrico e adaptação a ambientes áridos ou semiáridos, favorecendo a mesma a alcançar altas produções de biomassa nestes ambientes, sendo fundamental para a alimentação dos ruminantes nesta região (DUBEUX JÚNIOR et al.,2010; NOBEL, 2002).

A palma forrageira possui elevadas produções de matéria seca, variando de acordo com o sistema de plantio, tratos culturais e variedades, no entanto é comum observar-se produtividades de 10-20 ton.ha ${ }^{-1}$ M.S/ano (DE KOCK, 2001). Comparada com outras plantas forrageiras a palma é mais eficiente em produção.

O consumo excessivo e o mau uso da água vem provocando uma redução nos reservatórios, o que gera uma grande problemática na sociedade, devido a grande demanda por este recurso (OLIVO; ISHIKI, 2014). A irregularidade no regime 1-Graduando do Curso de Engenharia Agronômica , UFRN, ramonpablo197@gmail.com. 2-Mestranda do Programa de Pós Graduação em Produção Animal-PPGPA, UFRN, sueni_tec@ hotmail.com 3-Graduanda Curso de Zootecnia, UFRN, brenacampos16@ hotmail.com

4- Graduando Curso de Engenharia Agronômica, UFRN, alysson_linconl@ @otmail.com

5-Doutorado, Unidade Acadêmica Especializada em Ciências Agrárias-UFRN, emersonmaufrn@gmail.com 
pluviométrico do semiárido levam as culturas a sofrer com os efeitos adversos do déficit hídrico, o que acarreta em perdas de produção das plantas. Tendo em vista estes aspectos o uso dos chamados hidrogéis (polímeros oriundos do refino do petróleo) auxilia diretamente na disponibilidade de água ao vegetal, diminuindo os efeitos de um possível déficit hídrico.

Os polímeros hidroretentores, atuam absorvendo a umidade quando presente e gradativamente liberando-a de acordo com a perda de umidade do substrato, fato este que reduz os efeitos do déficit hídrico e a má distribuição das chuvas, impactando diretamente na cultura. Tendo em vista estes aspectos, este trabalho visa avaliar a utilização dos polímeros hidroretentores no cultivo da palma orelha de elefante mexicana.

\section{Fundamentação Teórica}

A má distribuição hídrica que o semiárido enfrenta, prejudica o desenvolvimento da produção vegetal na região, sendo necessário o uso de tecnologias para reverter esta situação, dentre estas tecnologias a utilização de polímeros de alta densidade, os chamados hidrogéis, propiciam além de fornecimento hídrico, controle na quantidade de água liberada, auxilio na melhoria dos aspectos físicos e químicos do solo, atuam como condicionante do solo e auxiliam a absorção de nutrientes (KLEIN; KLEIN, 2015), estes aspectos elevam o crescimento na utilização destes polímeros na agricultura.

É muito comum a utilização de cactáceas forrageiras, na alimentação dos animais desta região, dentre estas cactáceas a palma é a mais utilizada. Trata-se de um planta com metabolismo do tipo CAM, que a confere particularidades em relação as demais culturas em termos de utilização da água e em termos de produção de MS e MV.

A produtividade da palma em plantio adensado em regime de sequeiro é em torno de 300 t MV/dois anos (SANTOS et al, 2007). Já com suprimento hídrico observa-se produtividade na ordem de 450-500 t MV/ano (NOBEL, 1995). Em regiões áridas na ordem de 10 t MS/ano, em regiões semiáridas de 10-20 t MS/ano e em regiões subúmidas na ordem de 20-30 t MS/ano (DE KOCK, 2001).

Observou-se em diversos estudos que a palma possui uma grande resposta a adubação, orgânica ou química, com incrementos de produtividades significativos 
(LIMA et al, 2015; SUASSUNA, 2013; NOBEL, 1995). E quando não submetida a condições climáticas limitantes e ou déficit hídrico, comum em algumas regiões do semiárido, pode alcançar altas produções (DUQUE, 2004).

\section{Materiais e Metodologia}

$\mathrm{O}$ estudo foi conduzido na Unidade acadêmica Especializada em Ciências Agrárias, pertencente a Universidade Federal do Rio Grande do Norte, campus Macaíba/RN. O período entre plantio e a colheita da palma forrageira foi de janeiro de 2017 a fevereiro de 2018. A região apresenta características climáticas do tipo, tropical chuvosa e apresenta precipitação pluviométrica anual e temperatura média de aproximadamente $1.400 \mathrm{~mm}$ em ano chuvoso e $27^{\circ} \mathrm{c}$, respectivamente. $\mathrm{O}$ solo apresenta condição química de caráter distrófico.

O sistema de plantio utilizado na área é o de fileiras duplas (sistema baralho) com utilização da variedade de palma Orelha de Elefante Mexicana. Adotou-se para o plantio o sistema de adensamento em 5 fileiras duplas e formato de carta de baralho simples com espaçamento de $1,0 \times 0,5 \mathrm{~m} \times 1,0$ entre fileiras. Cada parcela apresentou uma área total de $56,25 \mathrm{~m}^{2}$.

O experimento foi dividido em 3 tratamentos com 6 repetições e 18 parcelas, com delineamento em blocos casualizados. E foram distribuídos da seguinte forma: (T1) - Testemunha sem a adição do hidrogel e sem adubação fluída. O Tratamento 2 (T2) aplicou-se aproximadamente $6 \mathrm{~g}$ do hidrogel agrícola por planta (adicionado hidratado) e adubação fluída via foliar constituída por MAP + uréia+ $\mathrm{Kcl}^{-}+$calcário líquido. O Tratamento 3 - (T3) a adubação utilizada foi fluída via foliar sem adição do hidrogel.

A adubação fluída ocorreu durante a noite, pois devido as características fisiológicas da palma forrageira, pelo seu metabolismo do tipo CAM (Metabolismo ácido das crassuláceas), a abertura dos seus estômatos ocorre durante a noite, diminuindo a perda de água e captando $\mathrm{CO} 2$ para o processo de fotossíntese. Assim a adubação durante a noite facilita a absorção dos nutrientes pela planta, que estar com os seus estômatos abertos para captação de $\mathrm{CO} 2$.

A primeira colheita ocorreu aos 12 meses após o plantio dispensando as bordaduras e utilizando a área útil de 11,25 m²/parcela abrangendo 3 fileiras duplas.

Para a determinação da matéria verde usou-se o peso da palma coletado na área útil e estimou-se a produtividade por hectare $\left(\mathrm{t} \mathrm{ha}^{-1}\right)$. E para determinação de MS (matéria seca) foram colhidas amostras em 10 plantas da área útil aleatoriamente. 
Houve mensuração de $1 \mathrm{~kg}$ de palma/área útil/repetição e conduzidos ao Laboratório de Nutrição Animal da UFRN, posteriormente foram picadas e submetidas à secagem na estufa de circulação forçada de ar a $65^{\circ} \mathrm{c}$ até atingir peso o constante.

Após obtenção dos dados de produção de massa seca das amostras, determinouse a produtividade de massa seca por tratamento e repetição estimando a produtividade por hectare $\left(\mathrm{t} \mathrm{ha}{ }^{-1}\right)$. As análises estatísticas realizadas foram utilizando testes via regressão múltipla e Anova com Turkey.

\section{Resultados e Discussões}

Observou-se a variável produtividade de Opuntia stricta, nos tratamentos analisados T1 (Testemunha), T2 (Hidrogel +Adubação líquida via foliar) e T3 (Adubação líquida via foliar). Foi observado influência do hidrogel e da adubação líquida na produtividade da palma forrageira Opuntia stricta, sendo o tratamento que recebeu o hidrogel e a adubação líquida o mais produtivo, seguido do tratamento que recebeu apenas adubação líquida. Os dois tratamentos foram superiores em relação ao tratamento testemunha.

Figura 1: Produtividade da palma forrageira OEM utilizando hidrogel e adubação fluída. Fonte:

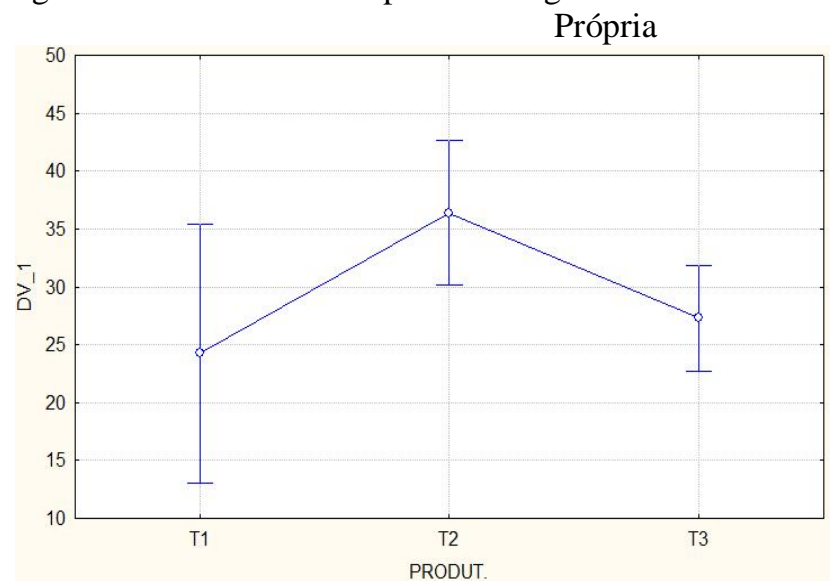

Produtividade; LS Means

Current effect: $F(2,10)$

$=6,2613, \mathrm{P}=01725$

Effective hypothesis decomposition vertical bars denote 0,95 confidence

Observou-se que o tratamento que recebeu o hidrogel foi o mais produtivo, conforme os dados da figura 1, corroborando assim para uma influência direta dos polímeros hidroretentores (hidrogel) na produção da palma forrageira Opuntia stricta, este fato pode ser justificado pela influência da água nos processos metabólicos da planta, na absorção de nutrientes e turgidez celular, que se relacionam diretamente com o desenvolvimento do vegetal (TAIZ e ZEIGER, 2009).

Estudos de LIMA et al., (2015) observaram valores semelhantes para palma irrigada e adensada na ordem de 35 t MS/ano, semelhantes aos 43 e 32 t MS/ano obtidos nos tratamentos T2 e T3 deste ensaio, respectivamente. O suprimento hídrico permitiu 
observar-se produtividade superior aos $300 \mathrm{t} \mathrm{MV/} \mathrm{dois} \mathrm{anos,} \mathrm{ou} 30 \mathrm{t} \mathrm{MS} /$ dois anos encontrados por SANTOS et al., (2007).

Notou-se que a utilização do hidrogel possibilitou um fornecimento de água para a planta, evitando assim que a mesma viesse a sofrer estresse hídrico, comum em certas localidades do semiárido e que acarreta em perdas de produção por murcha ou morte da planta (LIMA et al, 2015).

Houve diferença significativa para a variável produtividade de MV (matéria verde) e MS (matéria seca) entre os tratamentos avaliados, o tratamento com hidrogel e adubação líquida (T2) apresentou uma maior produção de MV e MS em toneladas por hectare, seguido pelo tratamento que recebeu a adubação líquida (T3), e o tratamento testemunha (T1) foi o que obteve menor produtividade de MV e MS no ensaio. Os valores obtidos nos tratamentos T2 e T3 deste ensaio para produção de MS estão de acordo com os de NOBEL (1995), que determinou que em ambientes subúmidos a produtividade da palma pode alcançar de 400-500 t MV/ano, ou 40-50 t MS/ano.

As respostas obtidas neste ensaio para as maiores produtividades de MV e MS da palma no tratamento T2, pode ser explicada pela utilização do hidrogel no T2 que permitiu retenção de umidade e liberação da mesma em períodos críticos de fornecimento de água, e o uso da adubação líquida via foliar na palma, que como se sabe este tipo de adubação permite redução nas perdas dos fertilizantes e uma aplicação localizada dos mesmos (MARTINS et al., 2010). Além de possibilitar misturas de nutrientes desde que sejam compatíveis. Este tipo de adubação é mais eficiente para gerar incrementos na produção da palma forrageira.

\section{Conclusões}

A utilização de polímeros de alta densidade no cultivo da palma forrageira permitiu um aumento de produtividade, com incrementos superiores aos demais tratamentos analisados no ensaio. A utilização de polímeros em união com a adubação líquida via foliar é fundamental para maiores produtividades da palma, pois fornece água e nutrientes para a cultura.

\section{Referências}

ARAÚJO, L. de F. et al. Equilíbrio higroscópico da palma forrageira: Relação com a umidade ótima para fermentação sólida. Revista Brasileira de Engenharia Agrícola e Ambiental, v.9,n.3, p.379-384, 2005.

DE KOCK, G. C. The use of Opuntia as a fodder source in arid areas of Southern Africa. 2001. Disponível em http://www.FAO.ORG/DOCREP/005/Y2808E/y2808e0f.htm> acesso em 23/08/2018 
DUBEUX JÚNIOR, J. C. B.; ARAÚJO FILHO, J. T.; SANTOS, M. V. F.; LIRA, M. A.;SANTOS, D. C.; PESSOA, R. A. S. Adubação mineral no crescimento e composição mineral da palma forrageira - Clone IPA-201. Revista Brasileira de Ciências Agrárias, Recife, v. 5, n. 1, p. 129-135, 2010.

DUQUE, J.G. Solo e água no polígono das secas. $6^{\circ}$ ed.-Fortaleza: Banco doNordeste, 2004. 334 p.

KLEIN, C.; KLEIN, V. A. Estratégias para potencializar a retenção e disponibilidade de água no solo. Revista do Centro de Ciências Naturais e Exatas, v. 19, n. 1, p. 21-29, 2015.

LIMA, G, F.C.; WANDERLEY...Palma forrageira irrigada e adensada: Uma reserva forrageira estratégica para o semiárido potiguar. Doc. EMPARN, ISSN 014197, Parnamirim, RN/outubro de 2015.

MARTINS, C.R.A.; Pereira, S.H.; Reis, F.E. Lecitina, silicone e amido na adubação foliar de couve (Brassica oleracea L.). Revista Ciência e Agrotecnologia, v.34, n.6, p.1470-1476, 2010. https://doi.org/10.1590/S1413-7054201000060001, acessado em $25 / 08 / 2018$

NOBEL, P. S.; BOBICH, E. G. Environmental biology. In: Nobel, P.S. (Ed.) Cacti: Biology and Uses. Berkeley, California: University of California Press, 2002. 280 p.

OLIVO, A. M.; ISHIKI, H. M. Brasil frente à escassez de água. Colloquium Humanarum, v. 11, n. 3, p. 41-48, 2014. 360 Revista Agro@mbiente On-line, v. 11, n. 4, p. 347-360, outubro-dezembro, 2017

SANTOS, D.C.; ARAÚJO, L. F.; LOPES, E.B. et al. Uso e aplicação da palma forrageira. In: LOPES, E.B. (ed) PALMA FORRAGEIRA: CULTIVO, USO ATUAL E PERPESCTIVAS DE UTILIZAÇÃO NO SEMIÁRIDO NORDESTINO. João Pessoa, PB: EMEPA-PB, FAEPA, 2007.p. 56-88

SUASSUNA, P. Tecnologia do cultivo intensivo da palma-TCIP. In: NAZARENO, M.A.; OCHOA, M.J.; DUBUEX Jr., J.C. Proceedings of the second meeting for the integral use cactos pear and other cacti. Santiago del Estero, Argentina: FAIICARDA CACTUSNET. 2013. P. 51-62

TAIZ, L.; ZEIGER, E. Fisiologia vegetal. 5. ed., Artmed, 2013. 918 p. 